\title{
TOP2A as marker of response to pegylated lyposomal doxorubicin (PLD) in epithelial ovarian cancers
}

\author{
Eleonora Ghisoni ${ }^{1,2}$, Furio Maggiorotto ${ }^{2}$, Fulvio Borella ${ }^{3}$, Gloria Mittica ${ }^{1,2}$, Sofia Genta ${ }^{1,2}$, Gaia Giannone ${ }^{1,2}$, \\ Dionyssios Katsaros ${ }^{3}$, Alberto Sciarrillo ${ }^{3}$, Annamaria Ferrero ${ }^{4}$, Ivana Sarotto ${ }^{2}$, Jessica Erriquez ${ }^{2}$, \\ Maria Flavia Di Renzo ${ }^{1,2}$, Massimo Aglietta ${ }^{1,2}$ and Giorgio Valabrega ${ }^{1,2^{*}}$
}

\begin{abstract}
Objective: Relapsed epithelial ovarian cancer (EOC) is frequently treated with pegylated liposomal doxorubicin (PLD). Unfortunately, most patients do not benefit from treatment. Prediction of response is crucial to optimize PLD use and avoid unnecessary toxicities. We aimed at assessing the value of topoisomerase II alpha (TOP2A) expression as predictive marker of response to PLD-based therapy in patients with relapsed EOCs.

Methods: We retrospectively analyzed Formalin Fixed Paraffin Embedded (FFPE) tissues from 101 patients with platinum resistant (PR) or partially platinum-sensitive (PPS) EOCs treated with PLD-based chemotherapy beyond second line in three referral cancer centers between January 2010 and June 2018. TOP2A expression was measured by immunohistochemistry (IHC): images of each sample were acquired by optical microscope and analyzed by using automatic counter software. Correlation between TOP2A expression and response to PLD was assessed. Since no cut-off for positivity has been validated yet, we dichotomized TOP2A expression based on a cut-off of 18\% (mean value in this study).
\end{abstract}

Results: TOP2A expression beyond cut-off was not prognostic for primary platinum-free interval in our series $(p=0.77)$ neither for optimal cytoreduction $(p=0.9)$. TOP2A > 18\% was associated with a longer time to progression (TTP) following PLD-treatment, although not statistically significant $(p=0.394)$. No difference was observed between PR and PPS patients' groups ( $p=0.445$ and $p=0.185$, respectively). Not unexpectedly, patients with TOP2A expression $>18 \%$ treated with PLD monotherapy achieved a longer TTP compared with PLD-doublet therapy $(p=0.05)$.

Conclusions: Our data suggest that TOP2A status might predict activity of PLD in patients with PR/PPS EOCs.

Keywords: Ovarian cancer, Topoisomerase 2 alpha, Pegylated liposomal doxorubicin

\section{Introduction}

Epithelial ovarian cancer (EOC) is the leading cause of death among women with gynecological malignancies with 22,400 estimated new cases in 2017 [1]. Optimal cytoreduction to no residual disease followed by adjuvant chemotherapy with platinum-taxane combination is the standard of care [2,3]. However, over $70 \%$ of patients with advanced stage diseases experience relapse

\footnotetext{
* Correspondence: giorgio.valabrega@ircc.it

${ }^{1}$ Department of Oncology, University of Torino, Torino, Italy

${ }^{2}$ Candiolo Cancer Institute-FPO- IRCCS, Strada Provinciale 142 km 3.95, 10060

Candiolo, Turin, Italy

Full list of author information is available at the end of the article
}

after front-line treatment [4]. Residual disease (R) at primary surgery and sensitivity to first-line platinum-based chemotherapy (PFI, platinum-free interval) still represent the major determinants of clinical outcome $[5,6]$. For partially platinum-sensitive patients (PPS), defined as progressed between six and twelve months after conclusion of first line platinum-therapy, standard options include a second line platinum-based-doublet chemotherapy or pegylated liposomal doxorubicin [PLD] - trabectedin. For platinum resistant ovarian cancers (PR), defined as progressing within 6 months from last platinum therapy, limited and debatable options are available [7]. In these patients, subsequent single-agent

(c) The Author(s). 2019 Open Access This article is distributed under the terms of the Creative Commons Attribution 4.0 International License (http://creativecommons.org/licenses/by/4.0/), which permits unrestricted use, distribution, and 
chemotherapies with non-platinum drugs show limited activity [8]. The most effective drugs include paclitaxel, gemcitabine, etoposide, topotecan and PLD [9-12].

PLD is one of the preferred drugs due to its favorable toxicity profile (absence of alopecia, limited cardiac toxicity, and only moderate hematological and skin toxicity) $[13,14]$. However, response rates range from 16 to $25 \%$. Consequently, to optimize the use of PLD and avoid unnecessary toxicities, prediction of response is crucial.

TOP2A gene is located on the locus q21 of chromosome 17 , close to the HER2 gene, and is responsible for coding the nuclear enzyme type 2 topoisomerase alpha (TOP2A) [15]. TOP2A plays a key role in DNA stability and represents one of the targets of chemotherapeutic agents, such as etoposide and anthracyclines [16-18]. Several retrospective analyses have already suggested a correlation between TOP2A status and response to anthracyclines in breast cancer, both as neoadjuvant and adjuvant treatment [19-23]. Conversely, in EOCs few studies have investigated the prognostic and predictive role of TOP2A. Heterogeneous results are mainly related with the use of different detection techniques such as immunohistochemistry (IHC), Real-Time Polymerase Chain Reaction (RT-PCR) and Fluorescent-In Situ Hybridization (FISH) [24-26].

The aim of our study was to assess the correlation between TOP2A protein expression and clinical outcome of patients following PLD-based treatment in both platinum partially-sensitive and platinum-resistant patients.

\section{Materials and methods}

\section{Patients' characteristics}

We screened a total of 128 patients with PR/PPS EOCs treated with PLD-based chemotherapy beyond second line in three different referral centers (Candiolo Cancer Institute FPO/IRCCS, Ordine Mauriziano Hospital and Sant'Anna Hospital) between January 2010 and April 2018. Among these, 27 cases were excluded due to non-complete medical records or unavailability of tumor material for IHC analysis. For each of the 101 selected patients, the following clinico-histopathological data were recorded: i) age at diagnosis; ii) morphological features of ovarian cancer including tumor histotype, grade (according to World Health Organization Classification of Tumours of Female Reproductive Organs, 4th Edition) and stage (according to the International Federation of Gynecology and Obstetrics [FIGO]); iii) PFI (Platinum-Free Interval) to last platinum-based therapy; iv) number of previous lines before PLD; v) PLD-based treatment scheme; vi): Cancer Antigen 125 (CA-125) pre- and post-PLD treatment; vii) best radiological response according to RECIST 1.1 criteria, if available; viii) BRCA status; ix) date of death or last follow up (FU). Complete patients' clinical data are reported in Table 1.
Table 1 Patients' characteristics

\begin{tabular}{|c|c|}
\hline Patient number & 101 \\
\hline Median age (years) & 60 \\
\hline \multicolumn{2}{|l|}{ Histological subtype } \\
\hline Serous & $79(78,3 \%)$ \\
\hline Endometrioid & $7(7 \%)$ \\
\hline Mucinous & $2(1,9 \%)$ \\
\hline Clear cell & $2(1,9 \%)$ \\
\hline Mixed & $3(2,9 \%)$ \\
\hline Other/not specifed & $8(8 \%)$ \\
\hline \multicolumn{2}{|l|}{ Grading } \\
\hline G1 & 0 \\
\hline G2 & $7(7 \%)$ \\
\hline G3 & $94(93 \%)$ \\
\hline \multicolumn{2}{|l|}{ Staging (FIGO) } \\
\hline IC & $1(0,9 \%)$ \\
\hline$\| \mathrm{A}$ & $4(3,9 \%)$ \\
\hline$\| \mathrm{B}$ & $7(7 \%)$ \\
\hline$\| I I A$ & $4(3,9 \%)$ \\
\hline$\| I B$ & $8(8 \%)$ \\
\hline IIIC & $56(55,5 \%)$ \\
\hline IV & $21(20,8 \%)$ \\
\hline \multicolumn{2}{|l|}{$\mathrm{PFI}$} \\
\hline$<6$ months & $65(64,4 \%)$ \\
\hline$\geq 6$ months & $36(35,6 \%)$ \\
\hline \multicolumn{2}{|c|}{ Number of previous chemoterapies } \\
\hline 1 & $82(87,3 \%)$ \\
\hline 2 & $10(10,6 \%)$ \\
\hline$\geq 3$ & $2(2,1 \%)$ \\
\hline \multicolumn{2}{|l|}{ PLD-based regimen } \\
\hline PLD monotherapy & $54(53,4 \%)$ \\
\hline Carbo-PLD & $30(29,7 \%)$ \\
\hline Trabe-PLD & $17(16,9 \%)$ \\
\hline \multicolumn{2}{|c|}{ CA-125 mean value $(\mathrm{UI} / \mathrm{mL})$} \\
\hline Pre-PLD treatment & 1142 \\
\hline Post-PLD treatment & 1493 \\
\hline \multicolumn{2}{|l|}{ BRCA status } \\
\hline BRCA 1-2 mutation & $11(10,9 \%)$ \\
\hline BRCA 1-2 wild-type & $12(11,9 \%)$ \\
\hline VUS/HRD & $6(5,9 \%)$ \\
\hline Unknown & $72(71,3 \%)$ \\
\hline
\end{tabular}

FIGO International Federation of Gynaecology and Obstretics, PFI Platinum Free Interval from first platinum-based therapy, PLD Pegylated Liposomal Doxorubicin, Carbo Carboplatin, Trabe Trabectidin, CA-125 Cancer Antigen 125 


\section{IRB approval}

In Italy, the National Regulation established that retrospective studies require a notification to the local ethical committee with the tacit consent formula. We therefore notified the Candiolo Cancer Institute ethical committee about the conduct of the study on August 2016. All patients included in our retrospective study were treated according with the ethical standards of our local committee on human experimentation and with the Helsinki Declaration.

\section{Immunoistochemistry}

FFPE tissue blocks of the above 101 cases were obtained from the archives of the Units of Pathology at Candiolo Cancer Institute (IRCCS), A.S.O. Ordine Mauriziano Hospital and Sant'Anna Hospital at Torino. Immunohistochemistry was performed as previously described [27] to detect topoisomerase II alpha using a monoclonal rabbit antibody (clone D10G9 Cell Signaling Technology). At least 10 images of each sample were acquired by optical microscope $(20 \times)$ connected with charge-coupled device (CCD) camera and analyzed by using automatic counter software (NIH ImageJ). Only cells with TOP2A nuclear signatures were considered as positive. TOP2A expression was calculated as the ratio between positive cells and a total of at least 500 cells in 10 different fields.

\section{Statistical analysis}

Time to progression (TTP) following PLD-based treatment was assessed as the time elapsed between PLD start and first tumor progression or death, whichever comes first. TTP was estimated by the Kaplan-Meier method and compared according to TOP2A expression using the log-rank test. Because no positivity cut-off has been validated, similar to other studies we dichotomized TOP2A expression based on the mean value of our cohort (18\%). A $p<0.05$ was considered statistically significant. All analyses were performed using the SPSS statistical software program, version 22.0 (IBM SPSS Inc., Chicago, IL, United States of America).

\section{Results}

In our series, more than $75 \%$ were serous high grade, G3, advanced stage (IIIC-IV) EOCs. PFI showed that almost $65 \%$ of the patients were platinum-resistant. Eighty-seven per cent of the patients received PLD as second-line therapy and more than $50 \%$ as single-agent.

All 101 cases analyzed showed nuclear TOP2A expression, which ranged from 2 to $48 \%$ of nuclear cell signature with a mean of $18 \%$ (Fig. 1).

No statistically significant association between TOP2A expression and tumor histotype, grading or PFI were found. TOP2A expression beyond cut-off was not prognostic for primary platinum-free interval in our series $(p=0.77)$ neither for optimal cytoreduction $(p=0.9)$.
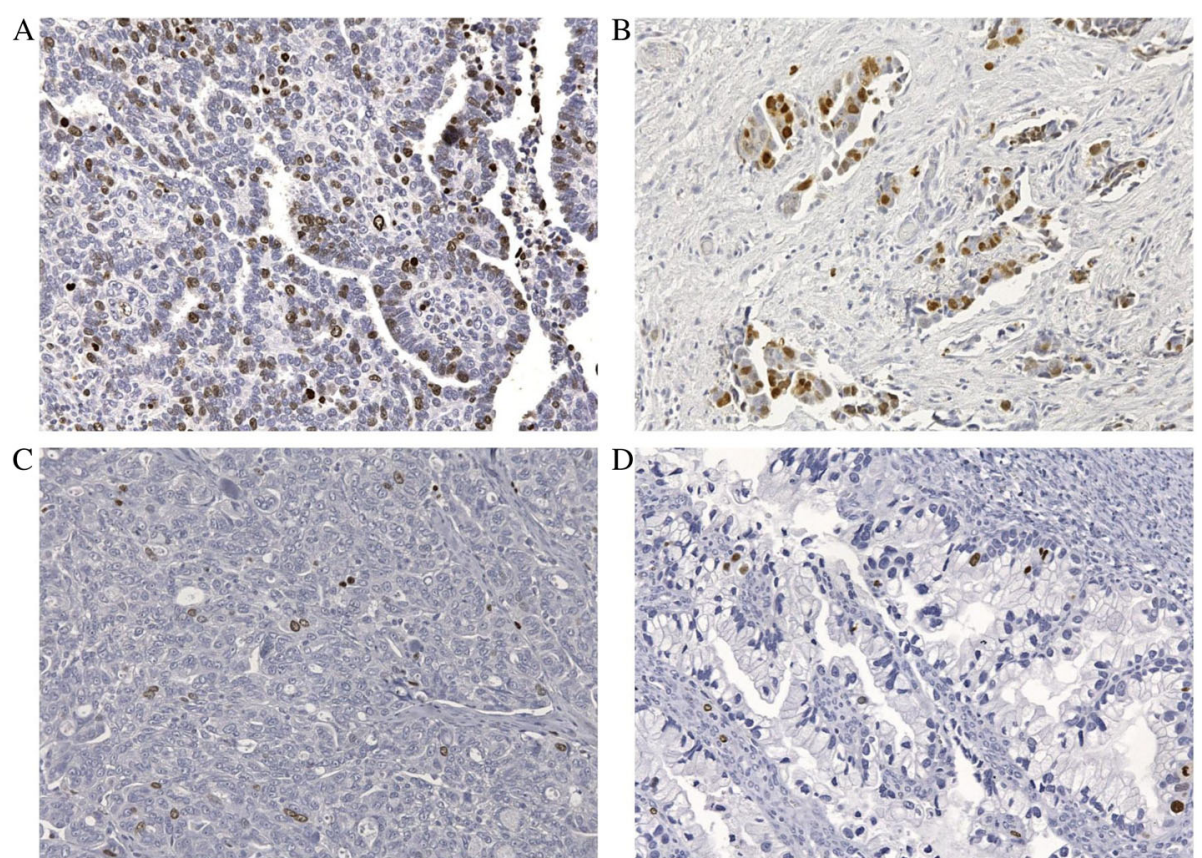

Fig. 1 TOP2A expression detected at IHC (images acquired by optical microscope 20x). a, b TOP2A over-expression above cut-off of 18\% nuclear cells signature versus. $\mathbf{c}, \mathbf{d}$ TOP2A expression below cut-off 

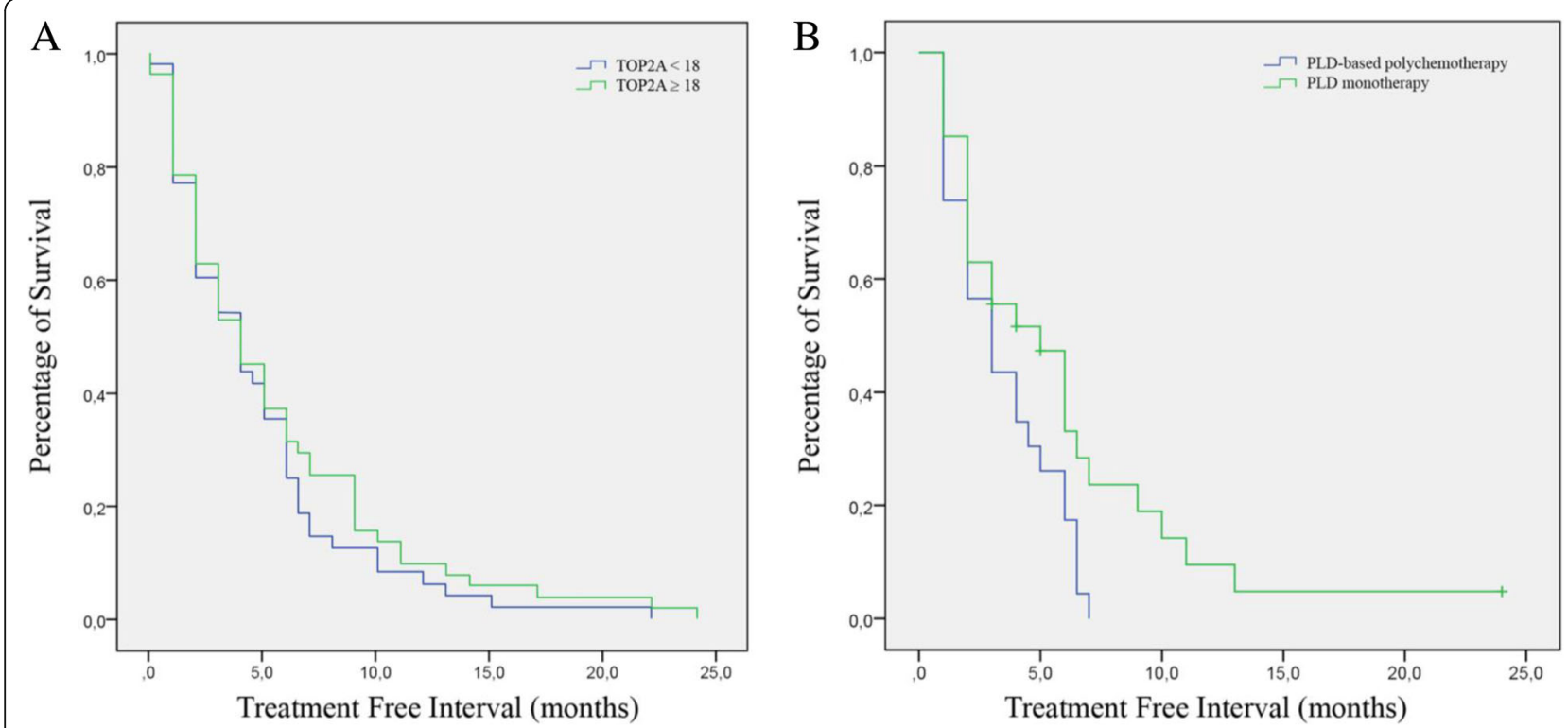

Fig. 2 Correlation between TOP2A expression and PLD-Treatment Free Interval. a Cases showing TOP2A expression above 18\% (mean value of this study) versus cases with TOP2A below cut-off limit. $\mathbf{b}$ Patients with TOP2A expression above $18 \%$ treated with PLD-monotherapy versus PLD-based polychemotherapy

Median time to progression from PLD-based treatment was 5, 1 months (range 1-24 months). Cancer Antigen 125 (CA-125) was above normal range in the 93\% of cases before PLD treatment (median value 1142 $\mathrm{UI} / \mathrm{dL}$ ) and in the $78,3 \%$ post-treatment (median value $1493 \mathrm{UI} / \mathrm{dL}$ ), but not statistical correlation was found between serological response and TOP2A status $(p=$ 0.285 ). TOP2A expression beyond cut-off was associated with a higher probability of response to PLD in terms of TTP, although not statistically significant $(p=0.0394$, Fig. 2a). No difference was observed between PR and PPS groups ( $p=0.445$ and $p=0.185$, respectively). Among the 67 patients with available radiological assessments, no difference could be observed in term of response: 31 patients obtained a disease control (partial response $[\mathrm{PR}]+$ stable disease $[\mathrm{SD}])$ and 36 progressed. Patients with TOP2A higher expression treated with PLD monotherapy achieved a longer TTP compared with PLD-doublet therapy $(5,8$ vs 3,4 months, $p=$ 0.035 , Fig. 2b). Complete results are summarized in Table 2.

BRCA germline-status was known in 29 patients. Among the eleven mutated patients, 7 carried a BRCA1 and 4 a BRCA2 mutations; twelve patients were wild-type and other six patients showed a variant of unknown significance (VUS). As expected, patients with BRCA mutations achieved a longer TTP (median 11 months, range 322, data not shown) compared with the median of our study population, although statistical analysis could not be performed due to the small numbers of cases.

Table 2 Correlation between TOP2A expression and response to Pegylated Lyposomal Doxorubicin (PLD) in terms of time to progression (TTP)

\begin{tabular}{llll}
\hline Time To Progression (TTP) to PLD & TOP2A < 18\% & TOP2A $\geq 18 \%$ & $p$-value \\
\hline All patients, months (Cl 95\%) & $4,5(3,1-5,9)$ & $6,7(4,8-8,6)$ & \\
TTP according to Platinum Free Interval & & & \\
PR & $3,7(2,6-4,9)$ & $4,9(2,9-6,9)$ & 0,445 \\
PPS & $5,6(2,7-8,6)$ & $9,1(5,8-12,4)$ & 0,185 \\
TTP according to chemoterapeutic regimen & & & $5,8(3,7-3,9)$ \\
PLD monotherapy & $3,4(2,5-4,3)$ & $9,6(5,7-13,5)$ & 0,035 \\
Carboplatin-PLD & $8,0(3,5-12,4)$ & $3,5(0,6-6,3)$ & 0,796 \\
PLD-Trabectidin & $1,8(0,6-3,2)$ & 0,358
\end{tabular}




\section{Discussion}

Treatment of patients affected by relapsed PR or PPS EOCs is still a major challenge for gynecologic oncologists and medical oncologists. To personalize the use of PLD and avoid unnecessary toxicities, prediction of response is of crucial importance. We have already demonstrated that TOP $2 A$ gene copy number is associated with protein overexpression and correlates with the activity of PLD in a small series of 38 PR EOCs and patients-derived xenografts (PDXs) [28]. Considering the concordance between TOP $2 A$ gene copy number and TOP2A protein expression, we aimed at developing a cost-effective and reproducible method (IHC) to assess the correlation between TOP2A and PLD activity. In our study we found that the prevalence of TOP2A expression is consistent with that observed by van der Zee at al [29]. and Faggad et al. [26] in their retrospective series. Moreover, we report here that TOP2A expression above $18 \%$ is associated with a higher probability of response to PLD in patients with PR/PPS EOCs. Finally, we showed that, regardless platinum-free interval, patients with TOP2A expression above cut-off, achieved a longer time to progression if treated with PLD monotherapy compared with PLD-doublet therapy $(p=0.035)$. These data may be explained by the known detrimental effect of poly-chemotherapy in pretreated patients [30, 31].

To our knowledge this is the biggest study investigating the role of TOP2A in predicting PLD activity in ovarian cancers.

However, our study has several limits. First of all the absence of a validated cut-off for TOP2A positivity at IHC impairs the reproducibility of the test. Moreover, assessment of TOP2A expression mainly at diagnosis may be discordant with TOP2A status at relapse, considering tumor heterogeneity and clonal evolution during progression. Finally our patient population was heterogeneous in terms of PFIs and PLD combinations.

Other predictors of sensitivity to anthracyclines have been studied. Among these, chromosome 17 polysomy, HER2, TIMP-1 [32], stroma-related genes and the immune response [33] have been already investigated with controversial results. More recently, defects in the homologous recombination system, such as BRCA1 and BRCA2 mutations have been associated with higher rates of response to platinum-based and anthracyclines regimens both in triple negative breast cancers (TNBCs) and EOCs [34].

In conclusion, although we believe that these results should be regarded as an hypothesis-generating attempt to identify a biomarker of response, only a multifactorial panel could be predictive of response to PLD in ovarian cancer [35].

\section{Abbreviations}

CA-125: Cancer Antigen 125; Carbo: Carboplatin; ECOG: Eastern Cooperative Oncology Group (ECOG); EOC: Epithelial ovarian cancer; FFPE: Formalin Fixed Paraffin Embedded; FIGO: International Federation of Gynecology and Obstetric; FISH: Fluorescent-In Situ Hybridization; IHC: Immunohistochemistry; PFI: Platinum-free interval; PLD: Pegylated liposomal doxorubicin; PPS: Partially platinum-sensitive; PR: Platinum-resistant; PS: Performance status; R: Residual tumor; RT-PCR: Real-Time Polymerase Chain Reaction; TNBCs: Triple negative breast cancers; TOP2A: Topoisomerase II alpha; Trabe: Trabectedin; TTP: Time to progression; VUS: Variant of unknown significance

\section{Acknowledgements}

None

\section{Funding}

This work has been supported by the following grant to GV: VALG_RIC_ LOC_14_01: Rete OncologicaPiemonte e Valle d'Aosta and Ministry of the University (ex 60\%, 2015) and to MFD IG\#16473 of the Italian Association for Cancer Research (AIRC).

Availability of data and materials

All data are available in the manuscript.

\section{Authors' contributions}

GV and EG conceived of the concept. EG, FB, AS, FM and GV participated in data collection and interpretation of results. GV, EG, GM and GG analyzed data and wrote the manuscript. All authors read and approved the final manuscript.

\section{Ethics approval and consent to participate}

Due to the retrospective nature of the study, informed consent was waived by the Medical Ethics Committee of Candiolo Cancer Institute, FPO/IRCCS Candiolo.

\section{Consent for publication}

Written informed consents for the publication of related Tables and figures had been obtained from the individuals.

\section{Competing interests}

The authors declare that they have no competing interests.

\section{Publisher's Note}

Springer Nature remains neutral with regard to jurisdictional claims in published maps and institutional affiliations.

\section{Author details}

${ }^{1}$ Department of Oncology, University of Torino, Torino, Italy. ${ }^{2}$ Candiolo Cancer Institute-FPO- IRCCS, Strada Provinciale 142 km 3.95, 10060 Candiolo, Turin, Italy. ${ }^{3}$ Department of Surgical Sciences, Gynecology, AOU Città della Salute, Torino, Italy. ${ }^{4}$ Department of Gynecology and Obstetrics, University of Torino, Mauriziano Hospital, Torino, Italy.

Received: 25 August 2018 Accepted: 31 January 2019

Published online: 13 February 2019

References

1. Miller KD, Siegel RL, Lin CC, Mariotto $A B$, Kramer $J$, Rowland $J H$, et al. Cancer treatment and survivorship statistics, 2016. CA Cancer J Clin. 2016; 66(4):271-89.

2. Ledermann JA, Raja FA, Fotopoulou C, Gonzalez-Martin A, Colombo N, Sessa C, et al. Newly diagnosed and relapsed epithelial ovarian carcinoma: ESMO Clinical Practice Guidelines for diagnosis, treatment and follow-up. Ann Oncol. 2013;24(Suppl 6):vi24-32.

3. Oza AM, Cook AD, Pfisterer J, Embleton A, Ledermann JA, Pujade-Lauraine E, et al. Standard chemotherapy with or without bevacizumab for women with newly diagnosed ovarian cancer (ICON7): overall survival results of a phase 3 randomised trial. Lancet Oncol. 2015;16(8):928-36.

4. Colombo N, Lorusso D, Scollo P. Impact of recurrence of ovarian Cancer on quality of life and outlook for the future. Int J Gynecol Cancer. 2017;27(6): 1134-40. 
5. du Bois A, Reuss A, Pujade-Lauraine E, Harter P, Ray-Coquard I, Pfisterer J. Role of surgical outcome as prognostic factor in advanced epithelial ovarian cancer: a combined exploratory analysis of 3 prospectively randomized phase 3 multicenter trials: by the Arbeitsgemeinschaft Gynaekologische Onkologie Studiengruppe Ovarialkarzinom (AGO-OVAR) and the Groupe d'Investigateurs Nationaux pour les etudes des cancers de l'Ovaire (GINECO). Cancer. 2009;115(6):1234-44.

6. Karam A, Ledermann JA, Kim JW, Sehouli J, Lu K, Gourley C, et al. Fifth ovarian Cancer consensus conference of the gynecologic Cancer InterGroup: first-line interventions. Ann Oncol. 2017;28(4):711-7.

7. Wilson MK, Pujade-Lauraine E, Aoki D, Mirza MR, Lorusso D, Oza AM, et al. Fifth ovarian Cancer consensus conference of the gynecologic Cancer InterGroup: recurrent disease. Ann Oncol. 2017;28(4):727-32.

8. Edwards SJ, Barton S, Thurgar E, Trevor N. Topotecan, pegylated liposomal doxorubicin hydrochloride, paclitaxel, trabectedin and gemcitabine for advanced recurrent or refractory ovarian cancer: a systematic review and economic evaluation. Health Technol Assess. 2015;19(7):1-480.

9. Lawrie TA, Bryant A, Cameron A, Gray E, Morrison J. Pegylated liposomal doxorubicin for relapsed epithelial ovarian cancer. Cochrane Database Syst Rev. 2013;7:CD006910.

10. Monk BJ, Herzog TJ, Kaye SB, Krasner CN, Vermorken JB, Muggia FM, et al. Trabectedin plus pegylated liposomal doxorubicin (PLD) versus PLD in recurrent ovarian cancer: overall survival analysis. Eur J Cancer. 2012;48(15): 2361-8.

11. Bozkaya $Y$, Doğan M, Umut Erdem G, Tulunay G, Uncu H, Arık Z, et al. Effectiveness of low-dose oral etoposide treatment in patients with recurrent and platinum-resistant epithelial ovarian cancer. J Obstet Gynaecol. 2017;37(5):649-54

12. Ferrandina G, Ludovisi M, Lorusso D, Pignata S, Breda E, Savarese A, et al. Phase III trial of gemcitabine compared with pegylated liposomal doxorubicin in progressive or recurrent ovarian cancer. J Clin Oncol. 2008; 26(6):890-6.

13. Krasner CN, Poveda A, Herzog TJ, Vermorken JB, Kaye SB, Nieto A, et al. Patient-reported outcomes in relapsed ovarian cancer: results from a randomized phase III study of trabectedin with pegylated liposomal doxorubicin (PLD) versus PLD alone. Gynecol Oncol. 2012;127(1):161-7.

14. Ferrandina G, Amadio G, Paris I, Distefano M, Palluzzi E, de Vincenzo R, et al. Real-world Management of Trabectedin/Pegylated liposomal doxorubicin in platinum-sensitive recurrent ovarian Cancer patients: a National Survey. Int J Gynecol Cancer. 2017;27(6):1141-8.

15. Nikolaou C, Bermúdez I, Manichanh C, García-Martinez J, Guigó R, PérezOrtín JE, et al. Topoisomerase II regulates yeast genes with singular chromatin architectures. Nucleic Acids Res. 2013:41(20):9243-56.

16. Roca J. Topoisomerase II: a fitted mechanism for the chromatin landscape. Nucleic Acids Res. 2009;37(3):721-30.

17. Li D, Yuan Z, Chen S, Zhang C, Song L, Gao C, et al. Synthesis and biological research of novel azaacridine derivatives as potent DNA-binding ligands and topoisomerase II inhibitors. Bioorg Med Chem. 2017;25(13):3437-46.

18. Nitiss JL. Targeting DNA topoisomerase II in cancer chemotherapy. Nat Rev Cancer. 2009;9(5):338-50.

19. Petit T, Wilt M, Velten M, Millon R, Rodier JF, Borel C, et al. Comparative value of tumour grade, hormonal receptors, Ki-67, HER-2 and topoisomerase II alpha status as predictive markers in breast cancer patients treated with neoadjuvant anthracycline-based chemotherapy. Eur J Cancer. 2004;40(2): 205-11.

20. Durbecq V, Paesmans M, Cardoso F, Desmedt C, Di Leo A, Chan S, et al. Topoisomerase-II alpha expression as a predictive marker in a population of advanced breast cancer patients randomly treated either with single-agent doxorubicin or single-agent docetaxel. Mol Cancer Ther. 2004;3(10):1207-14.

21. Di Leo A, Biganzoli L, Claudino W, Licitra S, Pestrin M, Larsimont D. Topoisomerase II alpha as a marker predicting anthracyclines' activity in early breast cancer patients: ready for the primetime? Eur J Cancer. 2008; 44(18):2791-8

22. Cardoso F, Di Leo A, Larsimont D, Gancberg D, Rouas G, Dolci S, et al. Evaluation of HER2, p53, bcl-2, topoisomerase II-alpha, heat shock proteins 27 and 70 in primary breast cancer and metastatic ipsilateral axillary lymph nodes. Ann Oncol. 2001;12(5):615-20.

23. Di Leo A, Desmedt C, Bartlett JM, Piette F, Ejlertsen B, Pritchard Kl, et al. HER2 and TOP2A as predictive markers for anthracycline-containing chemotherapy regimens as adjuvant treatment of breast cancer: a metaanalysis of individual patient data. Lancet Oncol. 2011;12(12):1134-42.
24. Slamon DJ. Studies of the HER-2/neu proto-oncogene in human breast cancer. Cancer Investig. 1990;8(2):253.

25. Koshiyama M, Fujii H, Kinezaki M, Morita Y, Nanno H, Yoshida M. Immunohistochemical expression of topoisomerase Ilalpha (topo Ilalpha) and multidrug resistance-associated protein (MRP), plus chemosensitivity testing, as chemotherapeutic indices of ovarian and endometrial carcinomas. Anticancer Res. 2001;21(4B):2925-32.

26. Faggad A, Darb-Esfahani S, Wirtz R, Sinn B, Sehouli J, Könsgen D, et al. Topoisomerase llalpha mRNA and protein expression in ovarian carcinoma: correlation with clinicopathological factors and prognosis. Mod Pathol. 2009;22(4):579-88.

27. Annaratone L, Marchiò C, Russo R, Ciardo L, Rondon-Lagos SM, Goia M, et al. A collection of primary tissue cultures of tumors from vacuum packed and cooled surgical specimens: a feasibility study. PLoS One. 2013;8(9): e75193.

28. Erriquez J, Becco P, Olivero M, Ponzone R, Maggiorotto F, Ferrero A, et al. TOP2A gene copy gain predicts response of epithelial ovarian cancers to pegylated liposomal doxorubicin: TOP2A as marker of response to PLD in ovarian cancer. Gynecol Oncol. 2015;138(3):627-33.

29. van der Zee AG, de Vries EG, Hollema H, Kaye SB, Brown R, Keith WN. Molecular analysis of the topoisomerase II alpha gene and its expression in human ovarian cancer. Ann Oncol. 1994;5(1):75-81.

30. Pujade-Lauraine $\mathrm{E}$, Alexandre J. Update of randomized trials in recurrent disease. Ann Oncol. 2011;22(Suppl 8):viii61-viii4.

31. Previs RA, Bevis KS, Huh W, Tillmanns T, Perry L, Moore $K$, et al. A prognostic nomogram to predict overall survival in women with recurrent ovarian cancer treated with bevacizumab and chemotherapy. Gynecol Oncol. 2014; 132(3):531-6.

32. Ejlertsen $B$, Jensen MB, Nielsen KV, Balslev $E$, Rasmussen BB, Willemoe GL, et al. HER2, TOP2A, and TIMP-1 and responsiveness to adjuvant anthracyclinecontaining chemotherapy in high-risk breast cancer patients. J Clin Oncol. 2010;28(6):984-90

33. Farmer $\mathrm{P}$, Bonnefoi $\mathrm{H}$, Anderle $\mathrm{P}$, Cameron $\mathrm{D}$, Wirapati $\mathrm{P}$, Becette $\mathrm{V}$, et al. $\mathrm{A}$ stroma-related gene signature predicts resistance to neoadjuvant chemotherapy in breast cancer. Nat Med. 2009;15(1):68-74.

34. Durbecq V, Desmed C, Paesmans M, Cardoso F, Di Leo A, Mano M, et al. Correlation between topoisomerase-llalpha gene amplification and protein expression in HER-2 amplified breast cancer. Int J Oncol. 2004;25(5):1473-9.

35. Desmedt C, Di Leo A, de Azambuja E, Larsimont D, Haibe-Kains B, Selleslags J, et al. Multifactorial approach to predicting resistance to anthracyclines. J Clin Oncol. 2011;29(12):1578-86.

Ready to submit your research? Choose BMC and benefit from:

- fast, convenient online submission

- thorough peer review by experienced researchers in your field

- rapid publication on acceptance

- support for research data, including large and complex data types

- gold Open Access which fosters wider collaboration and increased citations

- maximum visibility for your research: over $100 \mathrm{M}$ website views per year

At $\mathrm{BMC}$, research is always in progress.

Learn more biomedcentral.com/submission 